\title{
Studies Regarding the Influence of the Ultrasonication Conditions on the Adsorption Performance of Obtained Ionic Liquid Impregnated Materials
}

\author{
L. Lupa, A. Negrea, M. Ciopec, R. Vodă, and P. Negrea
}

\begin{abstract}
The influence of the ultrasonication conditions (time and amplitude of ultrasonication) upon the adsorptive properties of the obtained ionic liquid impregnated material, in the removal process of $\mathrm{Cs}^{+}$ions from aqueous solutions, was studied. In the last years ionic liquids was used for the treatment of waste waters containing radionuclides. In order to minimize the treatment cost and to enhance the treatment efficiency, as an alternative to liquid-liquid extraction processes, the use of ionic liquid impregnated support was proposed as a new concept. In the present paper the ultrasonication was used for the impregnation of 1-Butyl-3-methylimidazolium hexafluorophosphate-[BmimPF6] onto Florisil support. Different physical-chemical analysis (scanning electron microscopy (SEM), energy dispersive XRay analysis (EDX), and FTIR- Fourier transform infrared spectroscopy) was used to characterize the obtained ionic liquid impregnated material. In order to obtain a stable and homogenous impregnation of the solid support surface with the studied ionic liquid which will achieve reproducible results in the $\mathrm{Cs}^{+}$adsorption processes it is not necessary to increase the ultrasonication time, but it should be used higher amplitude. The adsorption performance of the Florisil impregnated with $\left[\mathrm{BmimPF}_{6}\right]$, using optimum conditions of ultrasonication, was studied as a function of $\mathrm{Cs}^{+}$ ions initial concentrations. Adsorption isotherms like Langmuir, Freundlich, Dubinin-Radushkevich (D-R), and Temkin were used to analyze the equilibrium data at different concentrations. The experimental data showed good fit to the Langmuir isotherm, followed by the Temkin and Dubinin-Radushkevich isotherms and then the least fit was obtained with the Freundlich isotherm.
\end{abstract}

Index Terms $-\mathrm{Cs}^{+}$adsorption, impregnation, ionic liquid, ultrasonication.

\section{INTRODUCTION}

The disposal of radioactive wastes is an issue relevant to almost all countries, therefore the studies regarding the removal of radioactive isotope from aqueous solutions are growing continually [1]-[4]. In recent years, ionic liquids (ILs) have gained a considerable attention and a choice to replace the volatile organic compounds (VOCs) in solvent extraction, due to their high thermal stability, very low flammability and negligible vapor pressure [5]-[11]. Therefore the researchers focused on the developing of another class of sorptive material through impregnation of various ionic liquid onto different solid support [10]-[13].

Manuscript received December 15, 2014; revised March 19, 2015

The authors are with the University Politehnica Timisoara, Faculty of Industrial Chemistry and Environmental Engineering, Blvd. V. Parvan, no.6, 300223, Timisoara, Romania (e-mail: lavinia.lupa@upt.ro).
Compared with liquid-liquid extraction, solid-liquid extraction provides an effective method for ILs application in separation. In this way a higher efficiency in the removal process of metals ions from aqueous solutions is obtained, because it took the advantages of the chemical functionality that ILs can impart and the properties of the solid support [10], [12]-[17]. Different methods of extractant impregnation onto various solid supports have been published such as: dry method of impregnation, encapsulation, sol-gel method, chemical immobilization [6], [7], [9], [11], [12], [18]-[22]. All these mentioned methods are quite time consuming; therefore an alternative green and economic process involving ultrasonication for the impregnation of the metal extractant was proposed [23], [24]. So far, there are no reports about the influence of the work condition of ultrasonication method upon the adsorbent properties of the obtained ionic liquid impregnated material. Therefore in the present paper was study the influence of the work condition of ultrasionication method upon the adsorption performance of the Florisil impregnated with 1-Butyl-3methylimidazolium hexafluorophosphate-[BmimPF 6 . This ionic liquid was chosen because the imidazolium based ionic liquids were intensive investigated in literature and showed higher stability [25]-[27]. An inorganic solid support was used due to highly porous texture and large specific surface area. The obtained Florisil impregnated with $\left[\mathrm{BmimPF}_{6}\right]$ at various work conditions of ultrasonication was subjected to a complex characterization scanning electron microscopy (SEM), energy dispersive XRay analysis (EDX), and Fourier transform infrared spectroscopy (FTIR). In order to determine the influence of the impregnation work condition upon the adsorbtive performance of the obtained material it was used in the removal process of $\mathrm{Cs}^{+}$ions from aqueous solutions.

\section{EXPERIMENTAL}

For the impregnation of the Florisil with the $\left[\mathrm{BmimPF}_{6}\right] \mathrm{IL}$ the time of ultrasonication (10-60 minutes) and the amplitude (10-100\%) using a Sonorex Super 10P ultrasonic bath, was varied. In all the experiments the ratio between the ionic liquid and solid support was kept at 0.1:1. Scanning Electron Microscopy (SEM) was used in order to investigate the changes of the surface morphology of the obtained adsorbent function of the impregnation conditions. SEM images were recorded using a Quanta FEG 250 Microscope, equipped with EDAX ZAF quantifier. The FTIR spectra (KBr pellets) of the obtained materials were recorded on a Shimadzu 
Prestige- 21 FTIR spectrophotometer in the range 4000-400 $\mathrm{cm}-1$. In order to establish the optimum conditions of impregnation, $0.1 \mathrm{~g}$ of obtained materials were treated with $25 \mathrm{~mL}$ of $10 \mathrm{mg} / \mathrm{L} \mathrm{Cs}{ }^{+}$ions solutions, obtaining the dependence of the $\mathrm{Cs}^{+}$ions uptake versus the ultrasonication time and amplitude. In these experiments the samples were stirred for $1 \mathrm{~h}$ using a Julabo SW23 shaker. After the time elapsed the samples were filtered and the residual concentration of $\mathrm{Cs}^{+}$ions was analyzed through atomic emission spectrometry using a Varian SpectrAA 280 type atomic absorption spectrometer using air/acetylene flame. The $\mathrm{Cs}^{+}$ions uptake was expressed using (1):

$$
q_{e}=\frac{\left(C_{0}-C_{e}\right) \cdot V}{m}
$$

where: $C_{0}$ and $C_{e}$ are the concentrations of $\mathrm{Cs}^{+}$ions $(\mathrm{mg} / \mathrm{L})$ in the solution initially $(t=0)$ and at equilibrium, respectively, $V$ is the volume of the solution and $\mathrm{m}$ is the mass of adsorbent.

For the Florisil impregnated with $\left[\mathrm{BmimPF}_{6}\right]$ in the recommended conditions established in the first step of the research, the maximum adsorption capacity in the removal process of $\mathrm{Cs}^{+}$ions from aqueous solutions was determined. In this aim the dependence of the $\mathrm{Cs}^{+}$ions uptake was determined varying the initial concentrations of $\mathrm{Cs}^{+}$ions from aqueous solutions (range 5-50 mg/L). Adsorption isotherms like Langmuir, Freundlich, Dubinin-Radushkevich (D-R), and Temkin were used to analyze the equilibrium data at different concentrations.

The linearized form of the Langmuir equation is given in (2) [9], [14], [19], [24]:

$$
\frac{C_{e}}{q_{e}}=\frac{1}{K_{L} \cdot q_{m}}+\frac{C_{e}}{q_{m}}
$$

where $q_{m}$ is the maximum adsorption capacity for a monolayer coverage, $K_{L}$ is a coefficient related to the affinity between the adsorbent and the adsorbate.

The linear form of the Freundlich isotherm equation is expressed in (3) [9], [14], [19], [24]:

$$
\ln q_{e}=\ln K_{F}+\frac{1}{n} \ln C_{e}
$$

where $K_{F}$ is a constant describing the adsorption capacity $(\mathrm{L} / \mathrm{mg})$ and $1 / n$ is an empirical parameter related to the adsorption intensity.

In (4) is given the linear form of Temkin isotherm model [19], [28]:

$$
q_{e}=\frac{R T}{b_{T}} \ln \left(K_{T}\right)+\frac{R T}{b_{T}} \ln \left(C_{e}\right)
$$

where $R T / b_{T}$ in $(\mathrm{J} / \mathrm{mol})$ corresponding to the heat of adsorption $R$ is the ideal gas constant, $T(K)$ is the absolute temperature, $b_{T}$ is the Temkins isotherm constant.

The linear form of the D-R isotherm is given in (5) [28]:

$$
\ln q_{e}=\ln q_{d}-B_{d}\left[R T \ln \left(1+\frac{1}{C_{e}}\right)\right]^{2}
$$

The apparent energy of adsorption, $E$ was calculated using (6):

$$
E=\frac{1}{\left(2 B_{d}\right)^{2}}
$$

The constant $q_{d}(\mathrm{~mol} / \mathrm{g})$ is the D-R constant representing the theoretical saturation capacity and $B_{d}\left(\mathrm{~mol}^{2} / \mathrm{J}^{2}\right)$ is a constant related to the mean free energy of adsorption per mole of the adsorbate, $R$ is the ideal gas constant $(8.314 \mathrm{~J} / \mathrm{molK}), T(K)$ is the temperature of adsorption, and $\mathrm{E}(\mathrm{kJ} / \mathrm{mol})$ is the mean free energy of adsorption per molecule of the adsorbate when transferred to the surface of the solid from infinity in solution.

\section{RESULTS AND DISCUSSION}

\section{A. Characterization of the Impregnated Florisil with [BmimPF $\left.{ }_{6}\right]$ Using Various Conditions of Ultrasonication}

The morphology of the $\left[\mathrm{BmimPF}_{6}\right]$ impregnated onto Florisil using various time of ultrasonication at amplitude of $100 \%$ is shown in Fig. 1.

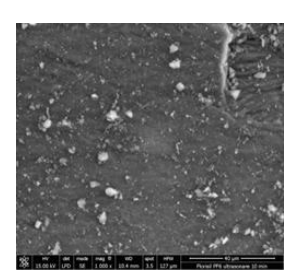

$10 \mathrm{~min}$

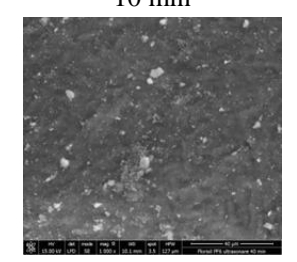

$40 \mathrm{~min}$

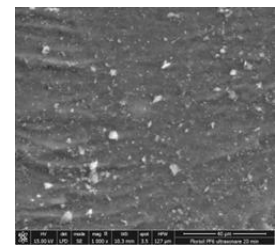

$20 \mathrm{~min}$

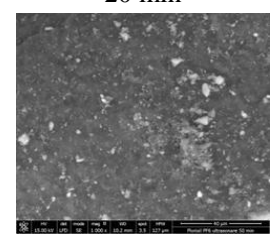

$50 \mathrm{~min}$

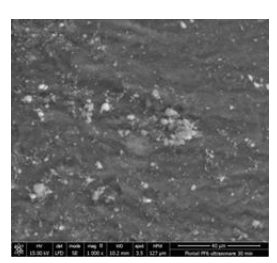

$30 \mathrm{~min}$

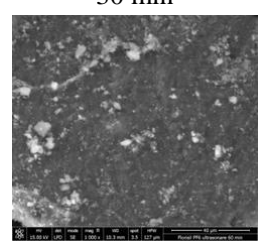

$60 \mathrm{~min}$

Fig. 1. SEM images of Florisil impregnated with $\left[\mathrm{BmimPF}_{6}\right]$ using various ultrasonication time. 
It can be observed that the increasing of the ultrasonication time lead to a patchy conglomeration of the studied IL onto the surface of Florisil support. The most uniform adherence of the IL particle onto the Florisil is obtained in case of 10 minutes of impregnation. Also at this time the adherence is deeper in the particles of the solid support, in this way the leaching of the IL from the solid support surface during the adsorption experiments is avoided. These results are significant in order to obtain reproducibility of the $\mathrm{Cs}^{+}$ adsorption process.

The intensity of sonication is proportional to the amplitude of vibration of the ultrasonic source and, as such, an increment in the amplitude of vibration will lead to an increase in the intensity of vibration and to an increase in the sonochemical effects. In our case the increasing of the amplitude lead to an increase in the IL quantity which is impregnated onto the Florisil surface.

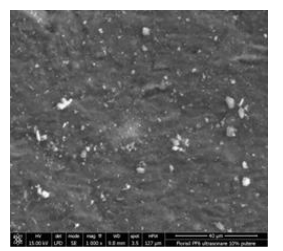

$10 \%$

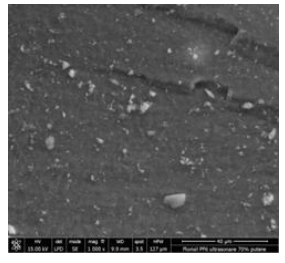

$70 \%$

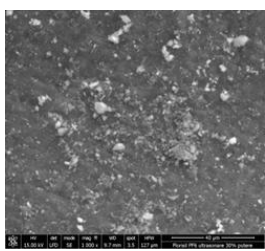

$30 \%$

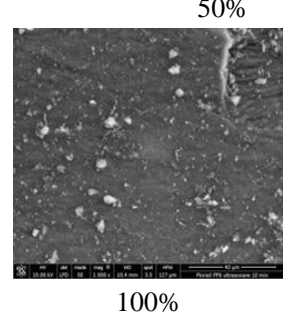

$100 \%$

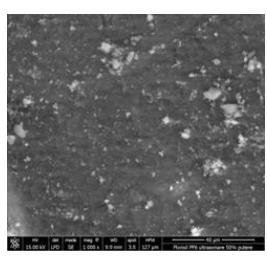

$50 \%$
Fig. 2. SEM images of Florisil impregnated with $\left[\mathrm{BmimPF}_{6}\right]$ using various ultrasonication amplitude.

From the SEM images of the materials obtained using various amplitude of ultrasionication for 10 minutes (Fig. 2) it can be observed that through the amplitude increasing is achieved an easier transmission of the IL particles through the liquid media until reach the cavities of the solid support. The phenomenon indicates that $\left[\mathrm{BmimPF}_{6}\right]$ did not coat on the surface of Florisil, while existed in the inner when amplitude of $100 \%$ is used for the impregnation through ultrasonication. This assures a higher stability of impregnation, avoiding the loss of IL from the surface of Florisil.

TABLE I: THE QUANTIFICATION OF P, F, AND N FOR THE OBTAINED IMPREGNATED MATERIALS RESULTED AT EDX ANALYSIS

\begin{tabular}{|c|c|c|c|c|c|c|c|}
\hline $\begin{array}{l}\text { Time of } \\
\text { ultrasoni- } \\
\text {-cation }\end{array}$ & $\begin{array}{c}P, \\
w t \%\end{array}$ & $\begin{array}{c}F, \\
w t \%\end{array}$ & $\begin{array}{c}N, \\
w t \%\end{array}$ & $\begin{array}{l}\text { Amplitude of } \\
\text { ultrasoni- } \\
\text {-cation }\end{array}$ & $\begin{array}{c}P \\
w t \%\end{array}$ & $\begin{array}{c}F \\
w t \%\end{array}$ & $\begin{array}{c}N, \\
w t \%\end{array}$ \\
\hline $10 \mathrm{~min}$ & 1.64 & 0.13 & 2.21 & $10 \%$ & 0.59 & 0.03 & 1.19 \\
\hline $20 \mathrm{~min}$ & 0.57 & 0.06 & 1.53 & $30 \%$ & 0.62 & 0.03 & 1.21 \\
\hline $30 \mathrm{~min}$ & 0.64 & 0.05 & 1.48 & $50 \%$ & 0.62 & 0.06 & 1.26 \\
\hline $40 \mathrm{~min}$ & 1.23 & 0.06 & 1.15 & $70 \%$ & 1.52 & 0.09 & 2.17 \\
\hline $50 \mathrm{~min}$ & 1.08 & 0.05 & 0.91 & $100 \%$ & 1.64 & 0.13 & 2.21 \\
\hline $60 \mathrm{~min}$ & 1.65 & 0.04 & 2.19 & & & & \\
\hline
\end{tabular}

In order to approve that the Florisil was impregnated with the studied ionic liquid, the obtained material were also subject to the EDX analyze. In Table I are presented the quantifications of $P, F$, and $N$ (specific elements from the ionic liquid which appear on the solid support due to the impregnation).

It can be observed from the results presented in Table I, that the quantifications are not conclusive influenced by the time of ultrasonication, obtaining random results. These confirm the fact that time increasing lead to the achieving of an unstable and patchy adherence of the ionic liquid onto the Florisil surface. On the other hand the increasing of the ultrasonication amplitude lead to the increasing of the P, F, and $\mathrm{N}$ quantifications. These indicate that the highest quantity of the $\left[\mathrm{BmimPF}_{6}\right]$ impregnated onto Florisil support is obtained when the impregnation method through ultrasonication is realized using an amplitude of $100 \%$ for 10 minutes. From these reasons we expect that the adsorbent obtained in these conditions will develop the highest efficiency in the removal process of $\mathrm{Cs}^{+}$from aqueous solutions.

Because from the SEM and EDX analyse was observed that the ultrasonication time hasn't a significant influence onto the impregnation process, only the samples obtained at various amplitude were submitted to the FTIR analyse. FTIR the spectra of the used ionic liquid $\left[\mathrm{BmimPF}_{6}\right]$, of the Florisil and of the Florisil impregnated with the ionic liquid at various amplitudes of ultrasonications are provided in Fig. 3. In the IR spectra of these compounds are found of the absorbtion bands from $\left[\mathrm{BmimPF}_{6}\right]$ vibrational spectrum (the bands between $2970-2850 \mathrm{~cm}^{-1}$ are stretching vibration of $\mathrm{CH}_{3}$ and $\mathrm{CH}_{2}$; the imidazolium $\mathrm{CH}$ stretching: $3125 \mathrm{~cm}^{-1}$, $3177 \mathrm{~cm}^{-1}$; the bands around $830 \mathrm{~cm}^{-1}$ and $740 \mathrm{~cm}^{-1}$ are attributed to the antisymmetric respectively symmetric stretching vibrations $\mathrm{PF}_{6}$ anion) [29]. The infrared spectra show that the highest quantity of $\left[\mathrm{BmimPF}_{6}\right]$ was impregnated onto Florisil when $100 \%$ amplitude was used (Fig. 3 g).

\section{B. Adsorption of $\mathrm{Cs}^{+}$from Aqueous Solutions}

The results regarding the adsorption capacity of material obtained at various work conditions of impregnation using a S:L ratio of $0.1 \mathrm{~g}: 25 \mathrm{~mL}$ of $10 \mathrm{mg} / \mathrm{L} \mathrm{Cs}^{+}$solution are presented in Fig. 4.

The obtained material through impregnation of Florisil with the studied ionic liquid using various time of ultrasonication developed random adsorption capacity in the removal process of $\mathrm{Cs}^{+}$ions from aqueous solution. It can be notice that the increasing of the ultrasonication time did not lead to an increasing of the adsorption performance of the obtained material.

On the other hand the increasing of the amplitude of ultrasonication in the process of Florisil impregnation with the studied ionic liquid lead to the increasing of the adsorption capacity of the obtained material. These results confirm the fact that the removal of $\mathrm{Cs}^{+}$ions from aqueous solutions is dependent by the quantity of ionic liquid impregnated onto the solid support. The results are in agreement with the conclusions resulted from the analysis of the impregnated materials. The most efficient adsorbent in 
the removal process of $\mathrm{Cs}^{+}$ions from a $10 \mathrm{mg} / \mathrm{L}$ solution proved to be the Florisil impregnated with $\left[\mathrm{BmimPF}_{6}\right]$ using a $100 \%$ amplitude of ultrasonication for 10 minutes. This material was treated with $\mathrm{Cs}^{+}$aqueous solutions having various concentrations (range: $5-50 \mathrm{mg} / \mathrm{L}$ ) in order to determine its maximum adsorption capacity. The adsorption isotherm of $\mathrm{Cs}^{+}$removal by the Florisil impregnated with $\left[\mathrm{BmimPF}_{6}\right]$ is presented in Fig. 5. It can be observed that the initial removal of $\mathrm{Cs}^{+}$is fast and at higher equilibrium concentration the adsorption capacity achieve a constant value.

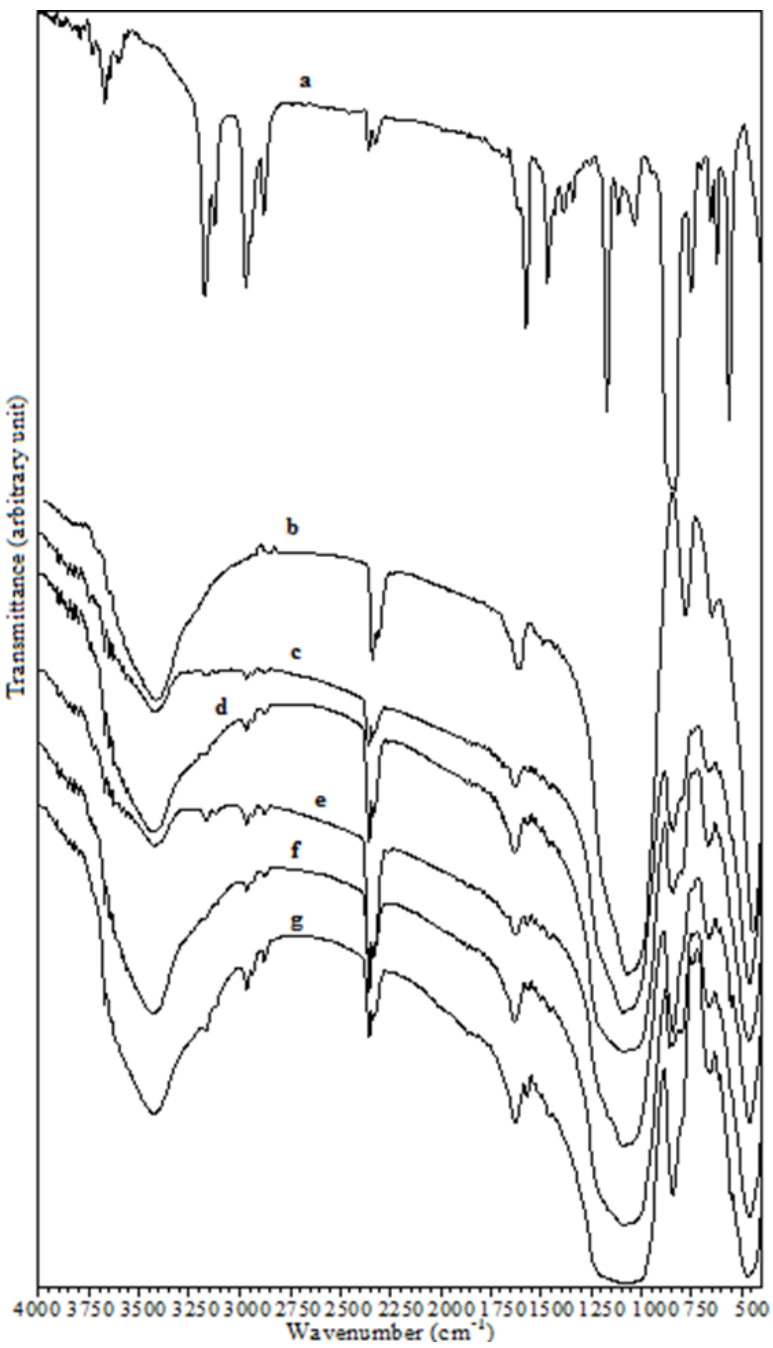

Fig. 3. The FTIR spectra of the a) $\left[\mathrm{Bmim} \mathrm{PF}_{6}\right]$; b) Florisil before impregnation; c) Florisil impregnated at $10 \%$; d) Florisil impregnated at $30 \%$; e) Florisil impregnated at 50\%; f) Florisil impregnated at $70 \%$; g) Florisil impregnated at $100 \%$.

The experimental data were fitted with Langmuir, Freundlich, Temkin, and Dubinin-Radushkevich isotherm models. The applying of Langmuir isotherm assume that once an adsorbate molecule occupies a site no further adsorption takes place and the forces of interaction between adsorbed molecules are negligible. In case of the Freundlich isotherm is assumed that the adsorption of the studied adsorbate onto the surface of the adsorbent is heterogeneous [9], [14], [19], [24]. Instead of Langmuir and Freundlich isotherm was used the Temkin isotherm which take into account the interaction between the adsorbent and $\mathrm{Cs}^{+}$ions to be absorbed being based on the free energy of adsorption as a simply function of surface coverage [19], [28]. In order to deduce the heterogeneity of the surface energies of adsorption and the characteristic porosity of the adsorbent the Dubinin-Radushkevich (D-R) isotherm model was applied to the data [28].
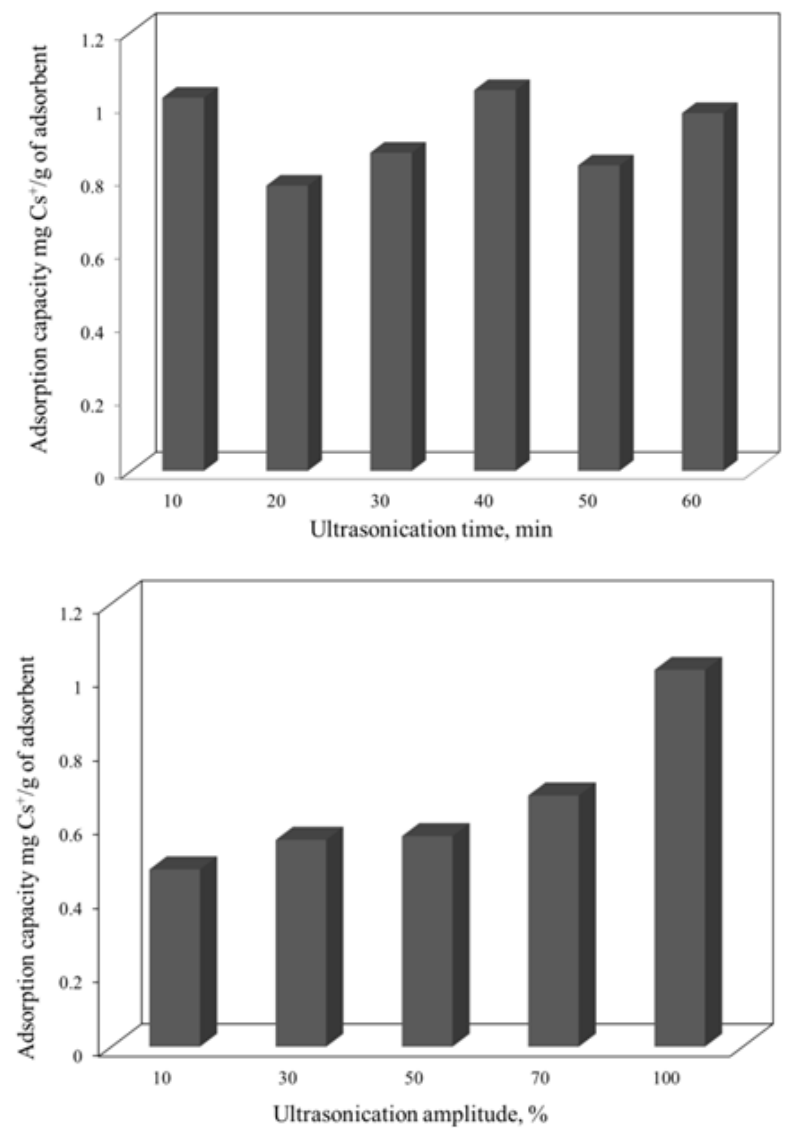

Fig. 4. Adsorption capacity versus the ultrasonication work conditions.

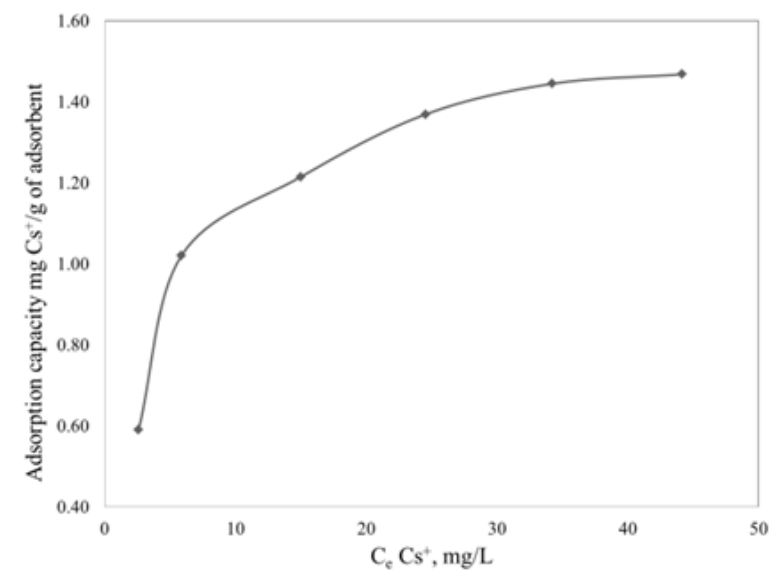

Fig. 5. $\mathrm{Cs}^{+}$adsorption isotherm onto the Florisil impregnated with $\left[\mathrm{BmimPF}_{6}\right]$.

The Langmuir constants $\left(K_{L}\right.$ and $\left.q_{m}\right)$ were obtained from the slope and intercept of the plot of $C_{e} / q_{e}$ against $C_{e}$ shown in Fig. 6. The Freundlich constants $(K F$ and $1 / \mathrm{n})$ were obtained from the plot of $\ln q e$ against $\ln C e$ (Fig. 7). From the slope and intercept of the linear plot of qe against lnCe (Fig. 8) were calculated the parameters of Temkin isotherm (KT and $b T$ ). The constants of the D-R isotherm were obtained from 
the plot and intercept of $\ln q e$ against $[R T \ln (1+1 / C e)]^{2}$ (Fig. 9). The constants of all isotherms and the regression coefficients are presented in Table II.

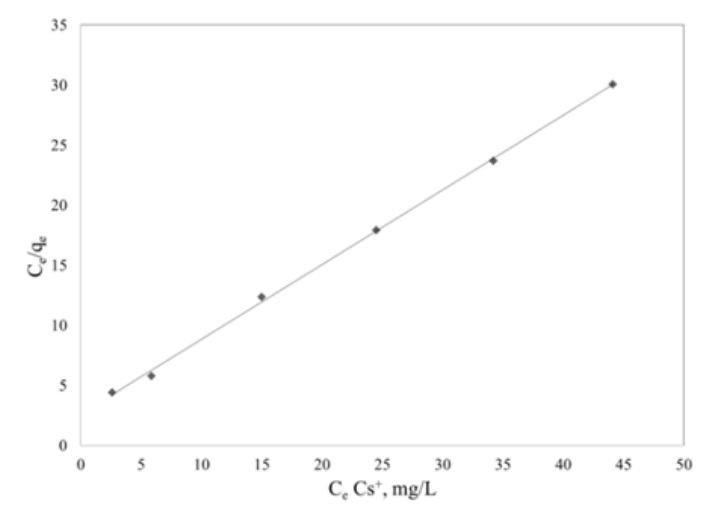

Fig. 6. Langmuir plot of $\mathrm{Cs}^{+}$adsorption onto Florisil impregnated with $\left[\mathrm{BmimPF}_{6}\right]$.

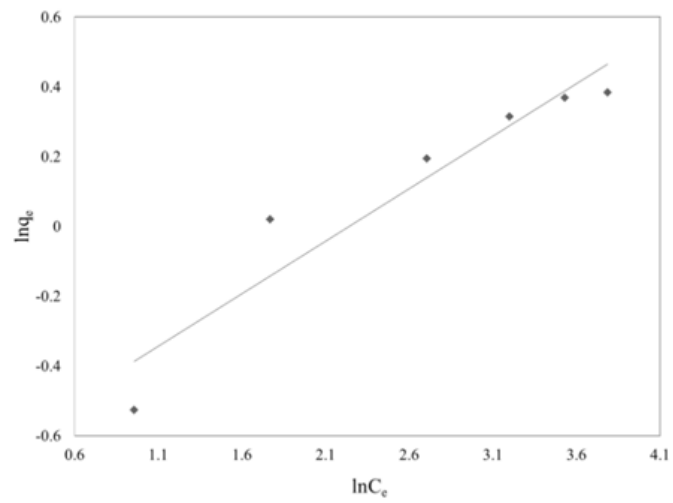

Fig. 7. Freundlich plot of $\mathrm{Cs}^{+}$adsorption onto Florisil impregnated with $\left[\mathrm{BmimPF}_{6}\right]$.

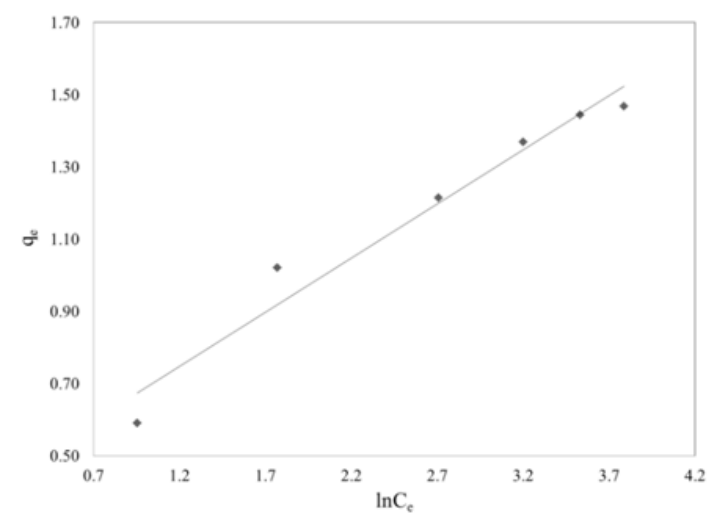

Fig. 8. Temkin plot of $\mathrm{Cs}^{+}$adsorption onto Florisil impregnated with $\left[\mathrm{BmimPF}_{6}\right]$.

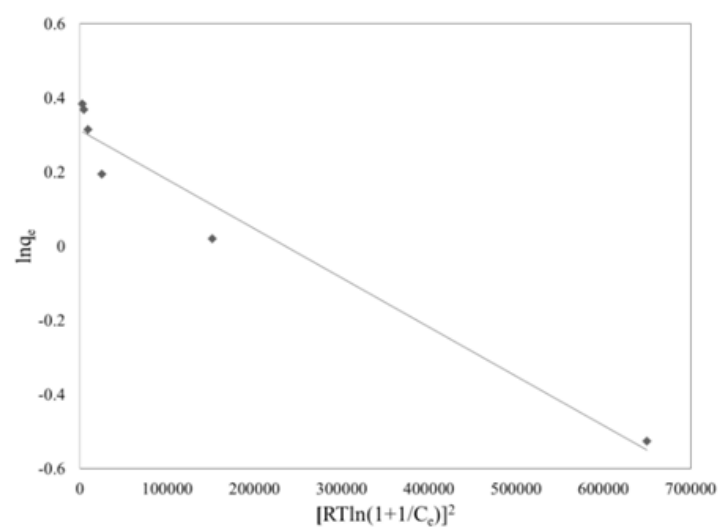

Fig. 9. D-R plot of $\mathrm{Cs}^{+}$adsorptiononto Florisil impregnated with $\left[\mathrm{BmimPF}_{6}\right]$.
TABLE II: EQUILIBRIUM ISOTHERM PARAMETERS

\begin{tabular}{|c|c|c|c|}
\hline \multicolumn{4}{|c|}{ Langmuir isotherm } \\
\hline$q_{m \text { exp }}, \mathrm{mg} / \mathrm{g}$ & $q_{m \text { calc }}, \mathrm{mg} / \mathrm{g}$ & $K_{L}, \mathrm{~L} / \mathrm{mg}$ & $R^{2}$ \\
\hline 1.47 & 1.6 & 0.24 & 0.9990 \\
\hline \multicolumn{4}{|c|}{ Freundlich isotherm } \\
\hline$K_{F}, \mathrm{mg} / \mathrm{g}$ & \multicolumn{2}{|c|}{$1 / \mathrm{n}$} & $R^{2}$ \\
\hline 1.96 & \multicolumn{2}{|c|}{0.30} & 0.9063 \\
\hline \multicolumn{4}{|c|}{ Temkin isotherm } \\
\hline$K_{T}, \mathrm{~L} / \mathrm{g}$ & $b_{T}$ & $\Delta G^{0}$ & $R^{2}$ \\
\hline 3.63 & 8.26 & -3.19 & 0.9624 \\
\hline \multicolumn{4}{|c|}{$\mathrm{D}-\mathrm{R}$ isotherm } \\
\hline$q_{d}, \mathrm{mg} / \mathrm{g}$ & \multicolumn{2}{|c|}{$E, \mathrm{~kJ} / \mathrm{mol}$} & $R^{2}$ \\
\hline 1.36 & \multicolumn{2}{|c|}{14.2} & 0.9575 \\
\hline
\end{tabular}

Comparing the isotherms applied, the Langmuir gave the best fit, followed by the Temkin and Dubinin-Radushkevich isotherms and then the least fit was obtained with the Freundlich isotherm. It can be notice that the Langmuir isotherm effectively describes the $\mathrm{Cs}^{+}$adsorption onto the studied adsorbent because is obtained a correlation coefficient closed to unity. The low values obtained for the Langmuir constant indicate that the Florisil impregnated with $\left[\mathrm{BmimPF}_{6}\right]$ has a high affinity for $\mathrm{Cs}^{+}$ions. Also in this case the obtained maximum adsorption capacity of the studied adsorbent in the removal process of $\mathrm{Cs}^{+}$ions from aqueous solutions is closed with that experimentally obtained. An important characteristic of the Langmuir isotherm is expressed in a dimensionless constant equilibrium parameter $R_{L}$. The $R_{L}$ value indicates the shape of the isotherm and is given in (7).

$$
R_{L}=\frac{1}{\left(1+K_{L} \cdot C_{0}\right)}
$$

The obtained $R_{L}$ values are between 0 and 1 indicating a favorable adsorption process. This suggests the applicability of these adsorbents in the removal process of $\mathrm{Cs}^{+}$ions from aqueous solutions. One important characteristic of the Freundlich isotherm is the $1 / n$ parameter which is below one indicating also a high affinity of the studied adsorbents for the $\mathrm{Cs}^{+}$ions. $K_{T}$ was used to determine the value of the Gibbs free energy of adsorption as follows:

$$
K_{T}=\exp \left(\frac{-\Delta G^{0}}{R T}\right)
$$

The negative values of $\Delta \mathrm{G}^{\circ}$ confirmed the feasibility of the process and the spontaneous nature of sorption. If the value of the $\mathrm{E}$ is higher than $8 \mathrm{KJ} / \mathrm{mol}$ the sorption process is a chemisorptions one, while values of below $8 \mathrm{KJ} / \mathrm{mol}$ indicates a physical adsorption process. The value of the apparent energy of adsorption obtained in this case indicates chemisorption between the Florisil impregnated with $\left[\mathrm{BmimPF}_{6}\right]$ and $\mathrm{Cs}^{+}$ions. 


\section{CONCLUSIONS}

The present paper showed that the work condition of ultrasonication impregnation method is important in order to enhance the adsorption capacities of the resulted adsorbents. In order to obtain a stable and homogenous impregnation of the solid support surface which will achieve reproducible results in the adsorption processes it is not necessary to increase the ultrasonication time, but we should use higher amplitude. In this way the studied ionic liquid $\left[\mathrm{BmimPF}_{6}\right]$ adhered inside the cavities of the Florisil, not only at the surface. Therefore the ultrasonication method is an efficient method of impregnation because a shorter time and smaller quantity of ionic liquids is used and the loss of the IL in the aqueous phase is avoided. The impregnated material obtained in the recommended conditions showed good adsorption performance in the removal process of $\mathrm{Cs}^{+}$from aqueous solutions, developing a maximum adsorption capacity of 1.6 $\mathrm{mg} / \mathrm{g}$. The experimental data showed good fit to the Langmuir isotherm, followed by the Temkin and Dubinin-Radushkevich isotherms and then the least fit was obtained with the Freundlich isotherm. The negative values of $\Delta \mathrm{G}^{\circ}$ confirmed the feasibility of the process and the spontaneous nature of sorption. The value of the apparent energy of adsorption obtained indicates chemisorption between the Florisil impregnated with $\left[\mathrm{BmimPF}_{6}\right]$ and $\mathrm{Cs}^{+}$ ions.

\section{ACKNOWLEDGMENT}

This work was supported by a grant of the Romanian National Authority for Scientific Research, CNCS UEFISCDI, project number PN-II-RU-TE-2012-3-0198.

\section{REFERENCES}

[1] C. Xu, X. Shen, Q. Chen, and H. Gao, "Investigation on the extraction of strontium ions from aqueous phase using crown ether-ionic liquid systems," Science in China Series B: Chemistry, vol. 52, no. 11, pp. 1858-1864, November 2009.

[2] A. Nilchi, R. Saberi, M. Moradi, H. Azizpour, and R. Zarghami, "Adsorption of cesium on copper hexacyanoferrate-PAN composite ion exchanger from aqueous solution," Chemical Engineering Journal, vol. 172, pp. 572-580, August 2011.

[3] A. M. E. Kamash, "Evaluation of zeolite a for the sorptive removal of $\mathrm{Cs}^{+}$and $\mathrm{Sr}^{2+}$ ions from aqueous solutions using batch and fixed bed columns operations," Journal of Hazardous Materials, vol. 151, pp. 432-445, March 2008.

[4] M. M. A. E. Latif and M. M. Elkady, "Kinetics study and thermodynamic behaviour for removing cesium, cobalt and nickel ions from aqueous solution using nano-zirconium vanadate ion exchange," Desalination, vol. 271, pp. 41-54, April, 2011.

[5] L. Lupa, A. Negrea, M. Ciopec, and P. Negrea, " $\mathrm{Cs}^{+}$removal from aqueous solutions through adsorption onto Florisil impregnated with trihexyl(tetradecyl) phosphonium chloride," Molecules, vol. 18, no. 10 pp.12845-12856, October 2013.

[6] X. Sun, Y. Li, J .Chen, and J. Ma, "Solvent impregnated resin prepared using task-specific ionic liquids for rare earth separation," Journal of Rare Earths, vol. 27, no. 6, pp. 932-936, December 2009.

[7] Y. Liu, X. Sun, F. Luo, and J. Chen, "Preparation of sol-gel materials doped with ionic liquids and thrialkyl phosphine oxides for Yttrium (III) uptake," Analytical Chimica Acta, vol. 604, pp. 107-113, December 2007.

[8] L. Guo, Y. Liu, C. Zhang, and J. Chen, "Preparation of PVDF-based polymer inclusion membrane using ionic liquid plasticizer and Cyphos IL 104 carrier for Cr(VI) transport," Journal of Membrane Science, vol. 372, pp. 314-321, April 2011.

[9] M. E. Mahmoud, "Surface loaded 1-methyl-3-ethylimidazolium bis(trifluoromethylsulfonyl)imide [EMIM+Tf $\left.\mathrm{T}_{2} \mathrm{~N}-\right]$ hydrophobic ionic liquid on nano-Silica sorbents for removal of lead from water samples,' Desalination, vol. 266, pp. 119-127, January 2011.

[10] X. Y. Yang, J. P. Zhang, L. Guo, H. Zhao, Y. Zhang, and J. Chen, "Solvent impregnated resin prepared using ionic liquid Cyphos IL 104 for Cr(VI) removal," Transaction of Nonferrous Metals Society of China, vol. 22, pp. 3126-3130, December 2012.

[11] Y. Liu, L. Zhu, X. Sun, J. Chen, and F. Luo, "Silica materials doped with bifunctional ionic liquid extractants for Yttrium extraction," Industrial \& Engineering Chemistry Reearch, vol. 48, pp. 7308-7313, July 2009.

[12] N. Fontanals, F. Borrull, and R. M. Marce, "Ionic liquids in solid-phase extraction," Trends in Analytical Chemistry, vol. 41, pp. 15-26, December 2012.

[13] T. Vincent, A. Parodi, and E. Guibal, "Immobilization of Cyphos IL-101 in biopolymer capsules for the synthesis of Pd sorbents," Reactive \& Functional Polymers, vol. 68, pp. 1159-1169, July 2008.

[14] L. Zhu, L. Guo, Z. Zhang, J. Chen, and S. Zhang, "The preparation of supported ionic liquids (SILs) and their application in rare metals separation," Science China Chemistry, vol. 55, no. 8, pp. 1479-1487, August 2012.

[15] J. Lemus, J. Palomar, M. Gilarranz, and J. Rodriquez, "Characterization of supported ionic liquid phase (SILP) materials prepared from different supports," Adsorption, vol. 17, no. 3, pp. 561-571, February 2011.

[16] A. Negrea, M. Ciopec, L. Lupa, P. Negrea, and A. Gabor, "Influence of the solid support base impregnated with IL on the sorption of various radionuclides from aqueous solutions," AWERProcedia Advences in Applied Science, vol. 1, pp. 241-250, March 2013.

[17] A. Negrea, L. Lupa, M. Ciopec, and P. Negrea, "Characterization of strontium adsorption from aqueous solutions using inorganic materials impregnated with ionic liquid," International Journal of Chemical Engineering and Applications, vol. 4, no. 5, pp. 326-331, October 2013.

[18] A. Arias, I. Saucedo, R. Navarro, V. Gallardo, M. Martinez, and E. Guibal, "Cadmium(II) recovery from hydrochloric acid solutions using Amberlite XAD-7 impregnated with a tetraalkyl phosphonium ionic liquid," Reactive \& Functional Polymers, vol. 71, pp. 1059-1070, November 2011.

[19] V. Gallardo, R. Navarro, I. Saucedo, M. Avila, and E. Guibal, “Zinc(II) extraction from hydrochloric acid solutions using Amberlite XAD7 impregnated with Chyphos IL101 (tetradecyl(trihexyl) phosphonium chloride)," Separation Science and Technology, vol. 43, pp. 2434-2459, August 2008.

[20] E. Guibal, A. F. Pinol, M. Ruz, T. Vincent, C. Jounanin, and A. Sastre, "Immobilization of Chypos ionic liquids in alginate capsules for $\mathrm{Cd}(\mathrm{II})$ sorption," Separation Science and Technology, vol. 45, pp. 1935-1949, 2010.

[21] L. Zhu, Y. Liu, and J. Chen, "Synthesis of N-methylimidazolium functionalized strongly basic anion exchange resins for adsorption of Cr(VI)," Industrial \& Engineering Chemical Research, vol. 48, pp. 3261-3267, February 2009.

[22] L. Zhu, C. Zhang, Y. Liu, D. Wang, and J. Chen, "Direct synthesis of ordered N-methylimidazolium functionalized mesoporous Silica as highly efficient anion exchanger of $\mathrm{Cr}(\mathrm{VI})$," Journal of Materials Chemistry, vol. 20, pp. 1553-1559, January 2010.

[23] S. Kalidhasan, S. K. Kumar, V. Rajesh, and N. Rajesh, "An efficient ultrasound assisted approach for the impregnation of room temperature ionic liquid onto Dowex $1 \times 8$ resin matrix and its application toward the enhanced adsorption of chromium (VI)," Journal of Hazardous Materials, vol. 213-214, pp. 249-257, April 2012.

[24] S. Kalidhasan, S. K. Kumar, V. Rajesh, and N. Rajesh, "Ultrasound-assisted preparation and characterization of crystalline cellulose-ionic liquid blend polymeric material: A prelude to the study of its application toward the effective adsorption of chromium," Journal of Colloid and Interface Science, vol. 367, pp. 398-408, February 2012.

[25] S. Keskin, D. K. Talay, U. Akman, and O. Hortacsu, "A review of ionic liquids towards supercritical fluid applications," Journal of Supercritical Fluids, vol. 43, pp. 150-180, November 2007.

[26] N. D. Khupse, and A. Kumar, "Ionic liquids: New materials with wide applications," Indian Journal of Chemistry, vol. 49, pp. 653-648, May-June 2010.

[27] H. Zhao, S. Xia, and P. Ma, "Review Use of ionic liquids as "green" solvent for extraction," Journal of Chemical Technology and Biotechnology, vol. 80, pp. 1089-1096, October 2005.

[28] A. Negrea, M. Ciopec, L. Lupa, C.M. Davidescu, A. Popa, G. Ilia, and P. Negrea, "Removal of AsV by FeIII - loaded XAD7 impregnated resin containing di(2-ethyl-hexyl) phosphoric acid (DEHPA): 
Equilibrium, Kinetic and Thermodynamic Modeling Studies," Journal of Chemical and Engineering Data, vol. 56, no.10, pp. 3830-3838, August 2011

[29] T. Buffeteau, J. Grondin, and J. C. Lassègues, "Infrared spectroscopy of ionic liquids: Quantitative aspects and determination of optical constants," Applied Spectroscopy, vol. 64, pp. 112-119, January 2010.

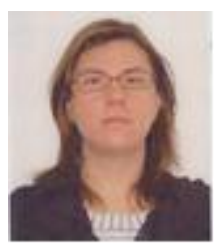

Lavinia Lupa was born on June 9, 1980 in Deva, Romania. She is currently a lecturer at Faculty of Industrial Chemistry and Environmental Engineering, University Politehnica Timisoara, Romania. She has obtained her $\mathrm{PhD}$ diploma in engineering science in 2008. Her teaching and research interests are in the environmental engineering and waste waters treatment.

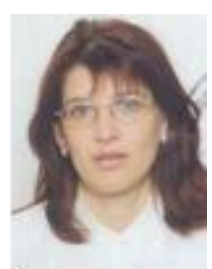

Adina Negrea was born on September 19, 1967 in Hunedoara, Romania. She is currently an assistant professor at Faculty of Industrial Chemistry and Environmental Engineering, University Politehnica Timisoara, Romania. She has obtained her PhD diploma in engineering science in 2002. Her teaching and research interests are in the environmental engineering and waste waters treatment.

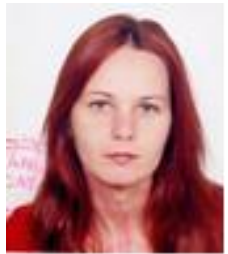

Mihaela Ciopec was born on October 8, 1977 in Timisoara, Romania. She is currently a scientific researcher at Faculty of Industrial Chemistry and Environmental Engineering, University Politehnica Timisoara, Romania. She has obtained her $\mathrm{PhD}$ diploma in engineering science in 2008. Her teaching and research interests are in the environmental engineering and waste waters treatment.

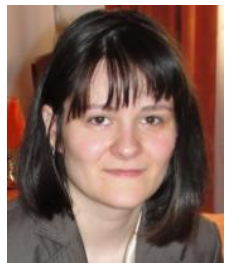

Raluca Vodă was born on June 19, 1978. She is currently a teaching assistant at Faculty of Industria Chemistry and Environmental Engineering, University Politehnica Timisoara, Romania. She has obtained her $\mathrm{PhD}$ diploma in Engineering Science in 2010. Her teaching and research interests are in the inorganic chemistry.

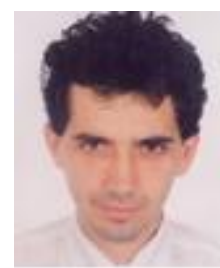

Petru Negrea was born on July 7, 1967 in Resita, Romania. He is currently a professor at Faculty of Industrial Chemistry and Environmental Engineering, University Politehnica Timisoara, Romania. He has obtained his $\mathrm{PhD}$ diploma in engineering science in 1996. His teaching and research interests are in the chemical engineering and environmental protection. 